\title{
Study on the packaging design of online shopping goods
}

\author{
Jiale Zhou ${ }^{1, \text { a }}$ \\ 1Panzhihua University, China \\ a38168006@qq.com
}

Keywords: online shopping goods; package design ; New demands

\begin{abstract}
Internet market has become the main sales channel in the era changing rapidly. Consumers change their consumption concepts, resulting in difficulties of traditional physical form of packaging in meeting the contemporary people's shopping patterns and aesthetic interests; therefore, the packaging design of online shopping goods arises at this historic moment. The innovative packaging of online shopping goods is based on the promotion of the Internet market and the online virtual trading market, as well as targeting at global consumers. The fashion and the unique way of online shopping in the Internet era has become the new orientation and design basis for the packaging of online shopping items. Unlike the package design of traditional shopping market, the most important characteristic of the package of online shopping goods is that consumers are unable to get practical shopping experience. How to make it accurately and clearly convey the information to help consumers make the right purchase decision and successfully complete the online trading is the principle of the package design of online shopping goods.
\end{abstract}

\section{Introduction}

\subsection{Online shopping goods}

It is a form of electronic commerce. It is a process of transferring goods or services from the merchant to the consumers by virtue of the network platform, so as to meet consumers' shopping needs and consumption concepts and realize the exchange of the interests between consumers and businessmen. It has become the main shopping trend in the present world. For online shopping customers, they will firstly browse the online item catalogs; then select their goods they need; finally, they will place online order and fulfill the online payment to finish the online trading. Thereafter, the supplier will make delivery according to the shipping order, and the whole transaction process is completed. Online shopping is the interest exchange among the Internet enterprises, between enterprises and consumers, among individuals, and between the government and enterprises (as shown in Table 1).

\section{Online shopping items classification}

\begin{tabular}{|l|l|}
\hline \multicolumn{1}{|c|}{ Criteria } & \multicolumn{1}{c|}{ Specific Types } \\
\hline Trading Patterns & between enterprises and consumers, among individuals \\
\hline Trading Bodies & $\begin{array}{l}\text { pure online retailers, traditional manufacturers, brands, } \\
\text { traditional channel traders }\end{array}$ \\
\hline Trading Objects & entity items, virtual goods, intangible items \\
\hline $\begin{array}{l}\text { The Electronic } \\
\text { Degree of the } \\
\text { Trading Process }\end{array}$ & completely electronic, incomplete electronic \\
\hline
\end{tabular}

Table 1 Online shopping items classification

\subsection{Packaging design of online shopping articles}

Online shopping goods package includes three forms. One package is for the sale goal, which usually contains the physical picture and text information of the goods. It is main channel for online shopper to identify and purchase goods. The second is the logistics transportation package for goods, which is the link between buyers and sellers to implement the online trading, and is also an indispensable package form in shopping online. The last one is the package for attached gifts, which is usually designed according to the type and properties of purchased products. 


\section{New demands of package design for online shopping goods in the Internet era. Online}

Shopping is different from the shopping in a physical store. The goods demonstration online is different from that in physical stores. And the purchase behavior of online shoppers also differs from that in physical stores. Naturally, they respectively have different appeals and demands for goods package design. Normally, we are able to see the package information of goods when shopping in physical stores. Consumers can make choices after comparing the specific items on display and the information on the package, because they know the items. While for online shoppers, they decide whether to make purchase only after comparing the pictures and the text introduction of goods, which is different from the purchase way of shoppers in physical stores. The role and significance of displaying items, decorative items and promotional items in the traditional package design cannot be demonstrated in online goods. Therefore, there is a special appeal for the package design of online shopping goods. Consumers' demand for online shopping goods (as shown in Table 2).

Online shoppers'demand

\begin{tabular}{|c|c|}
\hline $\begin{array}{l}\text { Classification } \\
\text { criteria }\end{array}$ & specific demands \\
\hline Safety & $\begin{array}{l}\text { avoid from deformation or deterioration caused by shock, vibration, high } \\
\text { temperature or low temperature }\end{array}$ \\
\hline $\begin{array}{l}\text { Environmental- } \\
\text { friendly }\end{array}$ & $\begin{array}{l}\text { use recyclable and regenerative packaging which is harmless to human } \\
\text { beings. }\end{array}$ \\
\hline Visibility & physical, virtual goods and intangible items \\
\hline Decoration & $\begin{array}{l}\text { design brief patterns and texts on the surface of packaging to prevent goods } \\
\text { from being damaged. }\end{array}$ \\
\hline
\end{tabular}

(Table 2 online shopping consumers’ demand)

\section{Tactics of packaging design of online shopping goods}

\subsection{The unique positioning of online shopping goods}

Since the items online shopping is a kind of form of consumption behavior in the 21st century, and occupies an increasingly large share in the market, part of goods should be considered to specially make for online shoppers at the moment when the manufacturer produces and packs the products. Considering that online shopping goods differ from the traditional goods in their factory packages, there should be a special positioning for online shopping goods. Thus, the design purpose and direction of goods packages will be very clear and also avoid the unnecessary packaging cost expenditure.

\subsection{The principle of function first}

Online shopping customers can only directly see the articles and the relevant descriptions and are unable to contact with the packages or to learn items from the packaging, so that the beautification, displaying, attraction functions etc. in the packaging promotion function are absolutely meaningless. At this point, the principle of packaging design is "function first", which mainly refers to the security protection function design and is in view of the promotion, beautification, display and other decorative designs. The packaging design of online shopping goods is focused on the safety of goods, including the safety in delivery, transportation, loading and unloading, storage, distribution, twice packaging, courier delivery at door and other aspects. Customers cannot contact with the packaging in the purchase of goods, but only at the time when the goods are delivered to the door. As for the good look, impressive appearance and elegance of packaging make no sense to customers.

\subsection{The identification of goods and customer information}

At present, the online shopping packings are mostly plastic bags, kraft corrugated cartons, plastic boxes, foam boxes and tapes etc. Some packages are like wounded persons wrapped by layers of paper tapes. It seems that they are picked up from the trash. What's more, the hand-writing or copied item information and customer information on the box are rather vague. And the similar size, shape and color of the packaging bags and boxes are made of the same materials, which are even difficult for the courier to identify. Customers are not clear about what they have purchased if they 
don't open the packaging unless they remember what they have bought. The design orientation for designers to consider is about how to better identify the items and customer information through the color, shape, mark and clear information column on the packaging box.

\subsection{The reuse and recycling of packaging}

Not only are customers aware of the importance of packaging safety, but also the businessmen are also trying to make safe packaging. Especially for the fragile goods, the merchants wrap goods three layers of packaging both inside and outside. When the customer receives a package from the courier, they always use both knives and scissors to cut open the layers. After the goods are taken out, the discarded packages form a pile, and have no value to be used again. They are simply a pile of rubbish. Therefore, when considering safety, we should also take the rationality of the safe structure, reuse chance, recycling and other issues into account. But not only should the merchants think about these, but also the courier companies commissioned to transport should. Especially for reuse of packaging, package of online shopping goods may be more reasonable, standardized and effective, as long as the courier company design and utilize different recyclable package according to different types of goods.

\section{Fresh experience of online shopping goods packaging design}

\subsection{Consumers' experience of value added products}

Online stores have more advantages over traditional stores dependent on repeated customers to gain development. Due to geographical and time constraints, traditional stores often cannot serve some customers want to buy again. For example, there are less repeated customers in stores located at tourist spots, stations and docks, while online stores are not subject to the restrictions of time and place. As long as they have made a good impression on consumers, it is possible for them gain many repeated customers and affect the numbers of online shopping consumers. Therefore, to encourage consumers to shop again is of great importance for the business development. For example, to put on a little thank-you card, discount card, welcome card, or some like that in the online shopping goods packaging will deliver a warm feeling to customers and will also enhance the impression of goods and stores on customers.

\subsection{Customers' experience of packaging materials}

In order to ensure the safety of online shopping goods in the long-term transportation before being received by customers, online goods packaging should be strong enough to prevent the happening of packing breakage, content leakage and loss, to prevent damage or deformation caused by misplacing, friction and vibration or by sunlight, air pressure and changes of air temperature and to prevent personal from being injured or transport equipment, ground equipment and other items from being polluted. Therefore, packaging materials of online shopping goods should not only adapt to nature, status and weight, but also should be clean, dry and without smell and grease. And there should have no convex screw, hook, thorn, etc. on the surface of outer packing. The packaging should also be easy to move, load, unload and display. Hence, in addition to the reasonable structure, many factors of the choice of packaging materials should be considered. Except the original packaging of goods, reasonable outer packaging and filling should also be selected according to the size, weight and characteristics of the goods.

\section{Conclusion}

Currently, online shopping has become one of the main ways of people to consume. Considering that online shopping goods are generally delivered singly, it is not only necessary for to emphasize the protection performance of product, but also to bring a close shopping experience to consumers in the packaging design of online shopping goods, so as to reproduce the original goods packaging by taking advantaging of the e-commerce platform under the online shopping mode. Therefore, customers cannot enjoy a convenient, fast and environmental-friendly life. 


\section{References}

[1] Xue Guo-you. Research on the Marketing Mode and Strategy of Small and Medium Sized Enterprises Under the E-Commerce[J] (in Chinese). Modernization of Shopping Mall. 2013 ( 11 ) : 105-106.

[2] Li Qiao-dan.Exploration of O2O Experiential Marketing Model[J] (in Chinese). E-Commerce. 2012 ( 9 ) :28-29.

[3] An Xiao-yan.Study and Analysis on the Design of Commodity Packaging in Network Market[J] (in Chinese). Journal of Shaanxi University of Science and Technology. 2011 ( 6 ) :32-33.

[4] Cha Yan, Wang Quanquan.Research on Ecological Packaging of Products Based on Online Shopping[J] (in Chinese). Modern Commercial and Trade Industry. 2012 ( 14 ) :103-104.

[5] Jiang Yu, Wu Yan-ye, Wang Xiao-fang.Changes and Problems of Commodity Packaging under the Mode of Online Purchase[J] (in Chinese). Printing Technology. 2015 ( 2 ) 42-45. 